\title{
An overview of NACA 6-digit airfoil series characteristics with reference to airfoils for large wind turbine blades.
}

\author{
W.A. Timmer ${ }^{1}$ \\ Delft University Wind Energy Research Institute, DUWIND, The Netherlands
}

\begin{abstract}
[Abstract] This paper investigates the NACA 63 and 64 6-digit series of airfoils tested in the NACA LTPT in view to verify the RFOIL calculated airfoil characteristics for high Reynolds numbers. Some anomalies in the zero-lift angles of $15 \%$ and $18 \%$ thick airfoils from these series are identified, both in the airfoil clean case and in case of wrap-around roughness. It is found that RFOIL predicts the maximum lift coefficient at a Reynolds number of 3 million well, but consistently under predicts the $C_{l, \max }$ for Reynolds numbers of 6 and 9 million. It is, however, based on other comparisons at high Reynolds numbers unclear if this is due to an inability of the prediction code or to a deviation in the test results. The drag coefficient is under predicted with about $9 \%$ for a wide range of airfoils and Reynolds numbers. Due to wrap-around roughness the maximum lift coefficient decreases with $18 \%$ to $20 \%$.
\end{abstract}

\section{Nomenclature}

$\begin{array}{ll}\alpha & =\text { angle of attack (degr.) } \\ C_{l} & =\text { lift coefficient } \\ C_{l, i} & =\text { design lift coefficient } \\ C_{l, \max } & =\text { maximum lift coefficient } \\ C_{d} & =\text { drag coefficient } \\ c & =\text { airfoil chord } \\ i & =\text { indication of design lift } \\ M & =\text { Mach number } \\ n & =\text { amplification factor in RFOIL } \\ R e & =\text { Reynolds number }\end{array}$

\section{Introduction}

$\mathrm{I}$ In the beginning of the revival of wind energy as an energy source in the seventies of the last century, NACA airfoils were adopted for wind turbine blades as a result of the availability of two-dimensional aerodynamic characteristics, even for airfoils with a fairly large relative thickness. The NACA four and five-digit series were later on abandoned for their sensitivity to roughness, but airfoils from the NACA 63 and 64 six-digit series are still being used in wind turbine blades today.

Since the seventies special wind turbine dedicated airfoil designs have found their way to blade and turbine manufacturers. Many of these designs were experimentally verified in wind tunnels up to Reynolds numbers of 3 to 4 million.

With the present trend towards very large turbines the Reynolds numbers have grown to about 10 million. Testing at these high Reynolds numbers is very expensive since this requires a large atmospheric tunnel, a pressure tunnel or a cryogenic tunnel. For all three types of facilities a fairly expensive model is needed as well. This leads to the situation that little experimental data is available for existing wind turbine dedicated airfoils at Reynolds numbers higher than 4 million. Blade designers now have to rely on the predictive value of airfoil analysis codes such as XFOIL or Navier-Stokes solvers.

Since the NACA airfoils we are discussing here were tested at Reynolds numbers up to 9 million these data can be used to verify the accuracy of the prediction codes and even a renewed interest for these airfoils may be noticed among wind turbine blade manufacturers.

${ }^{1}$ Assistant professor, TU Delft, Faculty of Aerospace Engineering, Kluyverweg 1, 2629HS Delft, The Netherlands 
The design and testing of the NACA airfoils some 70 years ago was a tremendous effort and rendered valuable information to many aerodynamicists world wide. However, when using it for verification, we have to take a closer look at the various test results. It appears that some anomalies in the data can be detected, which invites us to critically investigate all the relevant data.

In this paper the accuracy of these NACA measurements will be discussed and comparisons will be made with calculations and data from other facilities.

\section{Measurements in the Langley LTPT}

\section{A. Models}

The measurements of the well known NACA airfoils ${ }^{1}$ were performed in the Langley low-turbulence pressure tunnel. This is a pressure tunnel with a contraction ratio of 20:1 and a test section of $3 \times 7.5$ feet $(0.914 \mathrm{~m} \mathrm{x} 2.29 \mathrm{~m})$. The two feet $(0.61 \mathrm{~m})$ chord models were made of laminated mahogany. The model surface was painted with lacquer and sanded with no. 400 carborundum paper. The models completely spanned the three feet test section width. The maximum test section velocity at atmospheric pressure was about $130 \mathrm{~m} / \mathrm{s}$. The measurements had a maximum Mach number of 0.17 .

The airfoils considered here are airfoils from the 63 and 64 series designed in the forties of the last century. The shape of these airfoils is formed by the various thickness distributions and fractions of the $a=1$ camber line.

\section{B. Test setup}

The lift coefficient was determined using the difference of the pressure reaction upon the tunnel floor and ceiling. To this end pressure orifices are located over a length of 13 feet $(3.96 \mathrm{~m})$ on both floor and ceiling. Since this does not cover the entire pressure footprint of the model (which theoretically extends to infinity both upstream and downstream of the model) a lift efficiency factor was calculated which gives the ratio of measured lift to the actual lift, depending on the basic mean-line loading of the airfoil.

The drag coefficient was determined by integrating the total pressure loss in the wake, measured with a rake. Assuming the static pressure is constant across the wake and assuming the variation of the total pressure in the wake can be represented by a normal probability curve, the uncorrected drag was calculated using the static pressure coefficient and the maximum total pressure loss in the wake.

\section{Wind tunnel wall corrections}

To the lift and drag coefficients the basic corrections for blockage and lift interference have been applied, as given by Allen $\&$ Vincenti ${ }^{2}$.
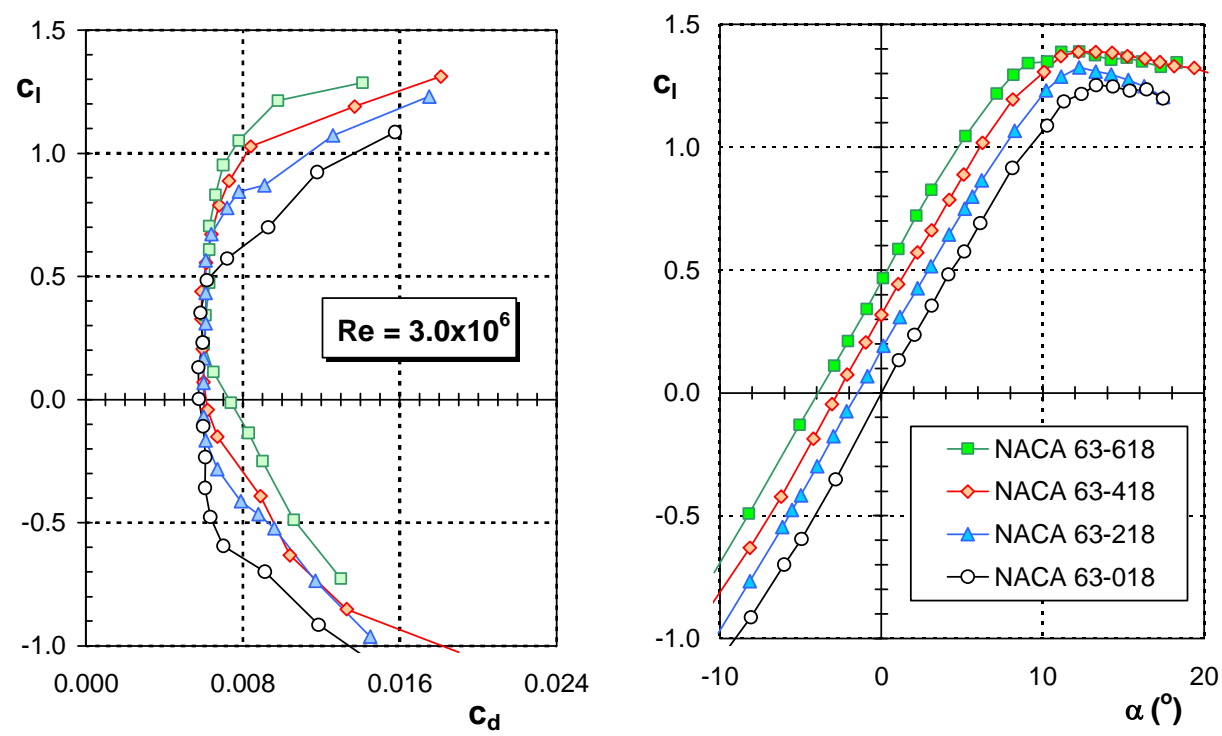

Figure 1. The effect of camber on the characteristics of an $18 \%$ thick airfoil from the NACA 63 6-digit series at a Reynolds number of $3 \times 10^{6}$. For clarity the indices in the airfoil designations have been omitted. 


\section{Two-dimensional aerodynamic characteristics}

The characteristics for the various airfoils presented here are digitized curves taken from reference 3 , since this report gives the largest and clearest graphs of the measured data.

\section{A. Lift curves}

In figure 1 the characteristics are depicted of the $18 \%$ thick airfoil with the 63 -series thickness distribution and with different camber lines derived from the $a=1$ camber line distribution. Due to the increased camber the lift curves shift to higher lift values at the same angle of attack and the low-drag buckets in the left hand graph shift along an envelop with a more or less constant minimum drag coefficient.
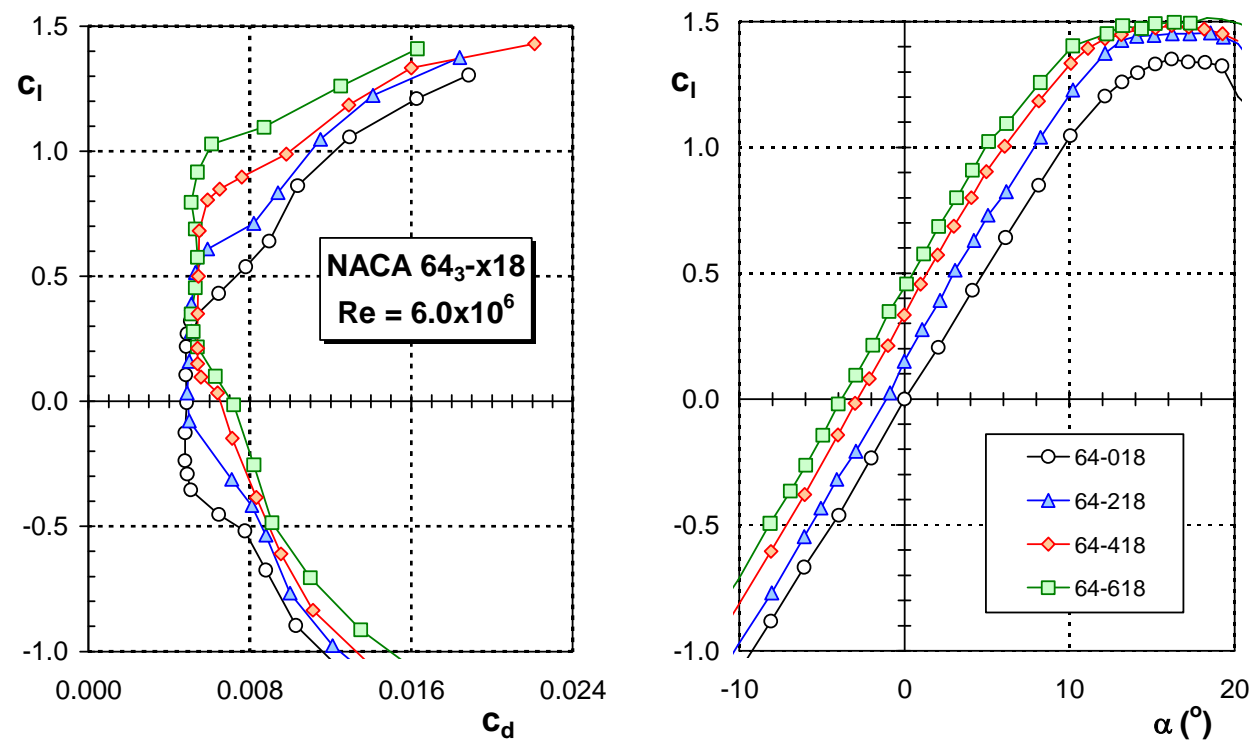

Figure 2a. The effect of camber on the characteristics of an $18 \%$ thick airfoil from the NACA 64 6-digit series at a Reynolds number of $6 \times 10^{6}$.
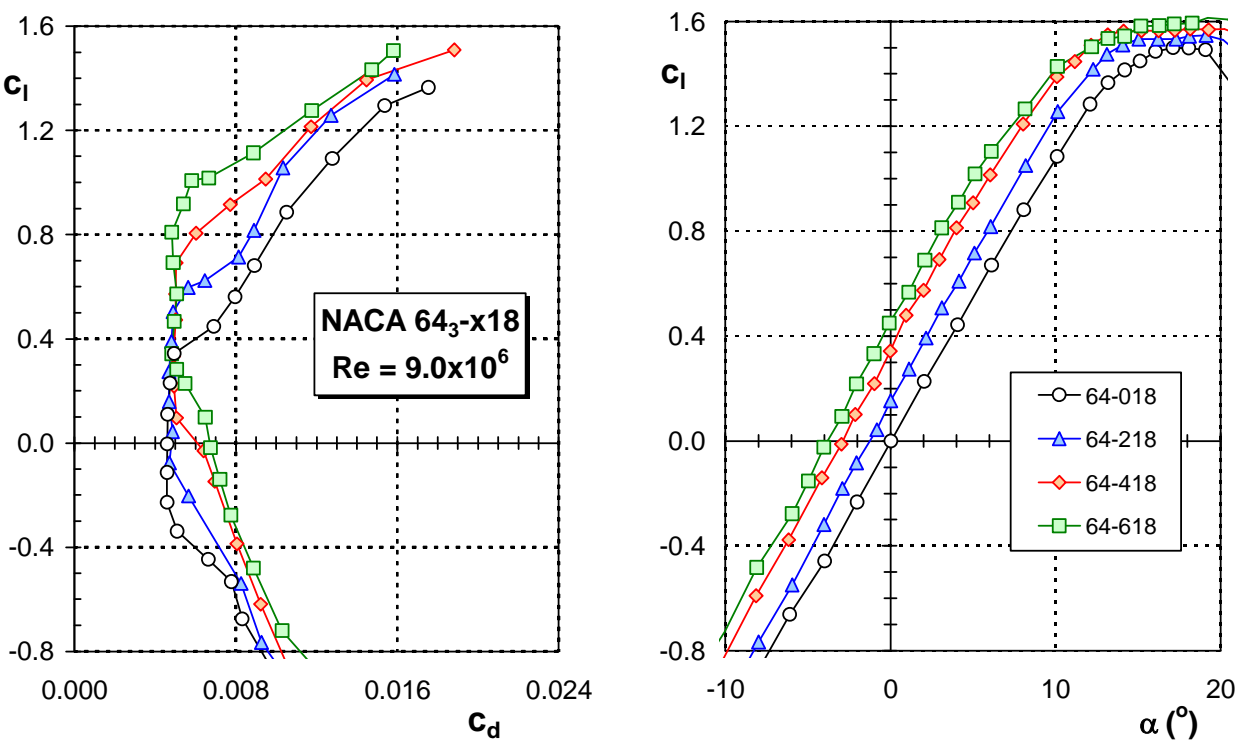

Figure 2b. The effect of camber on the characteristics of an $18 \%$ thick airfoil from the NACA 64 6-digit series at a Reynolds number of 9x10 . 
The graphs in the figures $2 \mathrm{a}$ and $2 \mathrm{~b}$ show basically the same aerodynamic behavior as in figure 1, now for the $18 \%$ thick airfoil from the NACA 64 series. However the lift curves are not equally spaced. If we study this in terms of the zero-lift angle of attack (see figure 3) we see a distinct difference in values for the different design lift coefficients. Also plotted in the graph are the calculated values using RFOIL ${ }^{4}$, a modified version of XFOIL and a measured value from reference 5. The RFOIL calculations were performed with a non-linear amplification scheme, which has an effect on the drag coefficient at the upper end of the low-drag region and consequently on the predicted maximum lift-drag ratio of the airfoil.

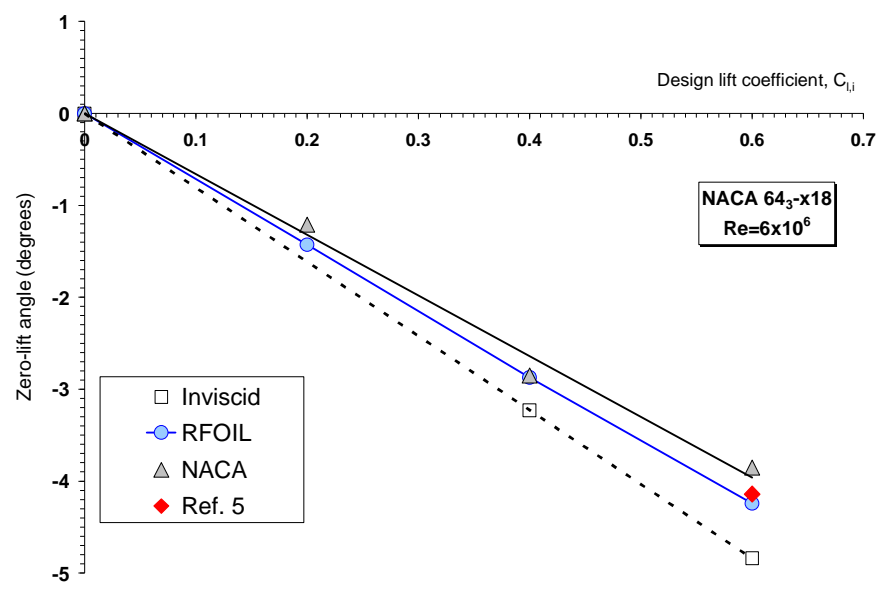

Figure 3. The zero-lift angle for an $18 \%$ thick airfoil from the NACA 64 series with different design lift coefficients. $\operatorname{Re}=6 \times 10^{6}$.

It must be noted that what here is called design lift coefficient differs from the commonly used definition, being the lift coefficient at which the maximum lift-drag ratio occurs. Here the design lift coefficient is derived from the fraction of the unit camber line and roughly gives the middle of the low-drag bucket.

Since the thickness distribution of the airfoils is the same and the camber line is formed by taking fractions of the same unit camber line the zero-lift angles essentially form a straight line. This is true for the inviscid values, but also for the angles calculated with RFOIL. The boundary-layer thickness de-cambers the airfoil, giving zero-lift angles closer to zero relative to the inviscid values. Since with increasing camber the upper surface adverse pressure gradients increase, giving thicker boundary layers, the distance between the inviscid and viscid curves grows with increasing $\mathrm{C}_{1, \mathrm{i}}$. Figure 3 shows that the measured zero-lift angle of NACA 64-618 is too small (about 0.4 degrees) compared to the theoretical value. As this difference occurs at every Reynolds number tested, it is most likely caused by the orientation of the model in the test section. Figure 4 shows the measured lift curve corrected with -0.4 degrees relative to RFOIL calculation.
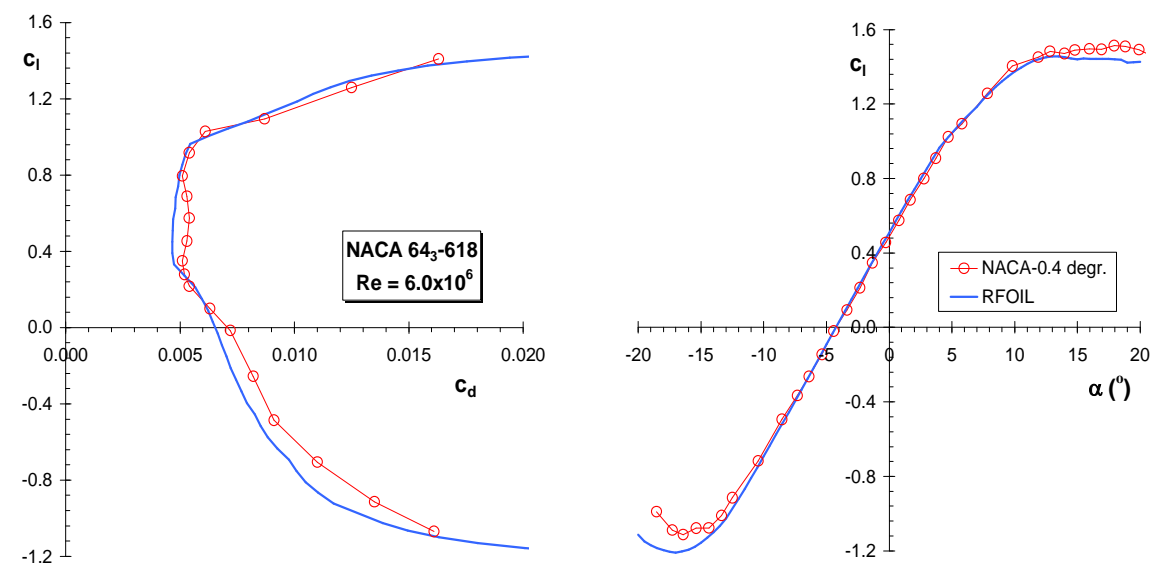

Figure 4. The measured performance of airfoil NACA $64_{3}-618$ at $\mathrm{Re}=6 \times 10^{6}$ relative to the calculations after modification of the zero-lift angle with -0.4 degrees. 


\section{B. Definition of airfoil chord.}

Another possible source for differences between theoretical zero-lift values and the measurements is the definition of the chord. In the NACA tradition the shape of the airfoil is the result of a camber line combined with a thickness distribution. In figure 5 the procedure is made visible, apart from the insertion of a nose circle to define the nose region with more points. With this scheme it is likely that the airfoil leading edge projects forward of the y-

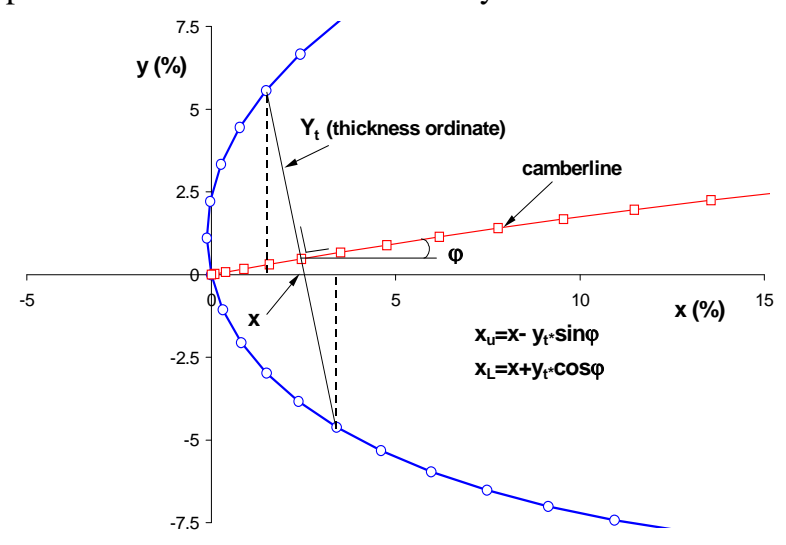

Figure 5. The NACA-procedure to establish the airfoil co-ordinates

axis. The airfoil should be redefined, with the chord now connecting the leading edge and the trailing edge (the longest distance).

Reference 2 refers to the chord as being the original $\mathrm{x}$-axis for the camber distribution. Would this definition be maintained in the wind tunnel than the zero-lift angle would be different relative to the redefined airfoil shape on the longest distance. On the other hand, if the unmodified originally calculated coordinates would be fed to a program like XFOIL, the characteristics are calculated relative to the original chord. Since the original chord for the camber line is hard to find in the actual wind tunnel model, it is assumed that all measurements are performed relative to the right (longest) chord.
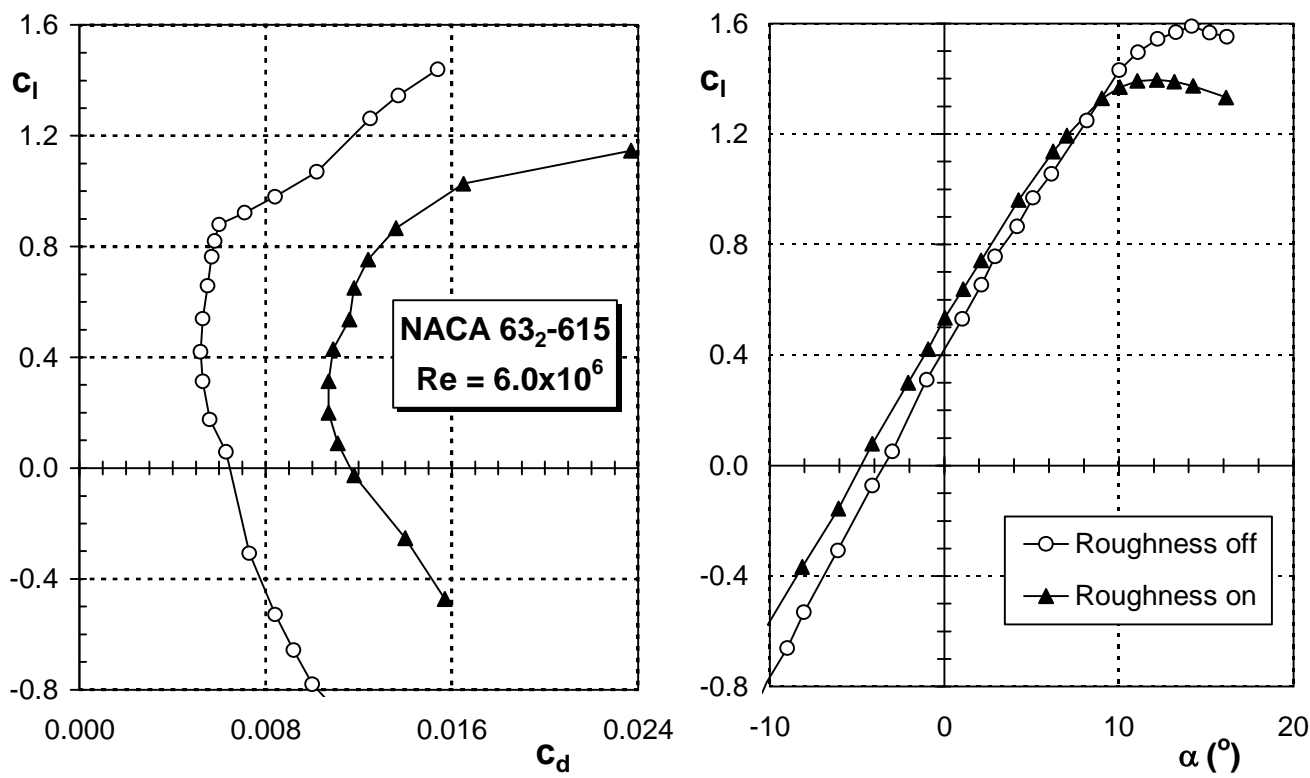

Figure 6. The effect of wrap-around roughness on the characteristics of airfoil NACA $63_{2}-615$ at $\operatorname{Re}=6 \times 10^{6}$. 


\section{Zero-lift angle in relation to roughness.}

Figure 6 depicts the characteristics of the NACA $63_{2}-615$ airfoil with and without NACA standard roughness. According to this graph up to 8 degrees angle of attack the airfoil shows improved lift performance due to wraparound roughness. Unfortunately this can not be true. Figure 7 provides a closer look at the zero-lift angles relative to those for $15 \%$ thick airfoils from the 63 -series with different design lift coefficients.

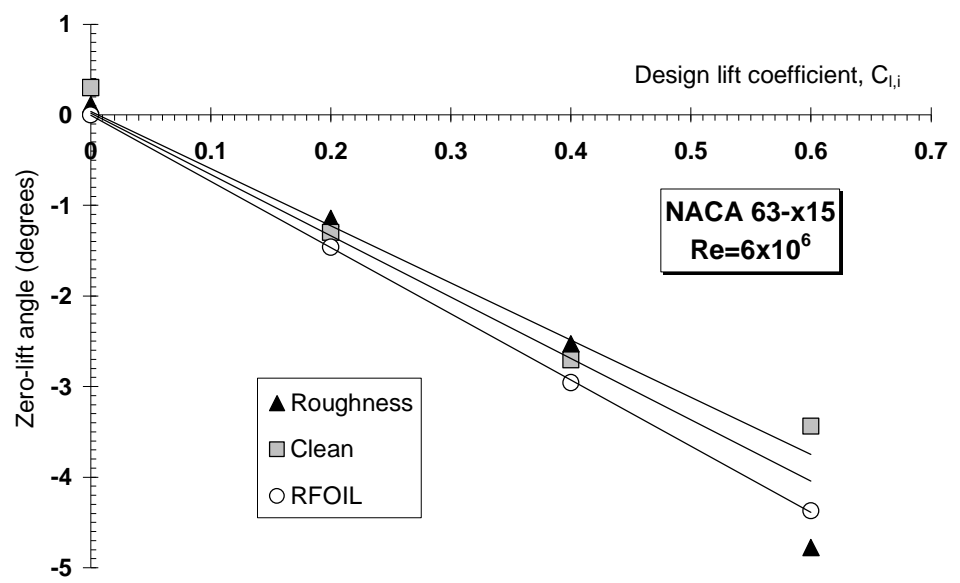

Figure 7. The effect of wrap-around roughness on the zero-lift angles for $15 \%$ thick airfoils in the NACA 63-series

The figure shows the trend in zero-lift angles and clearly the ones for a design lift coefficient of 0.6 do not follow the trend lines.

In the roughness off case the zero-lift angle should lie around $-4.27^{\circ}$ while $-3.44^{\circ}$ was measured. In the rough situation $-4.78^{\circ}$ was measured, whereas the trend line indicates a value of $-3.75^{\circ}$.
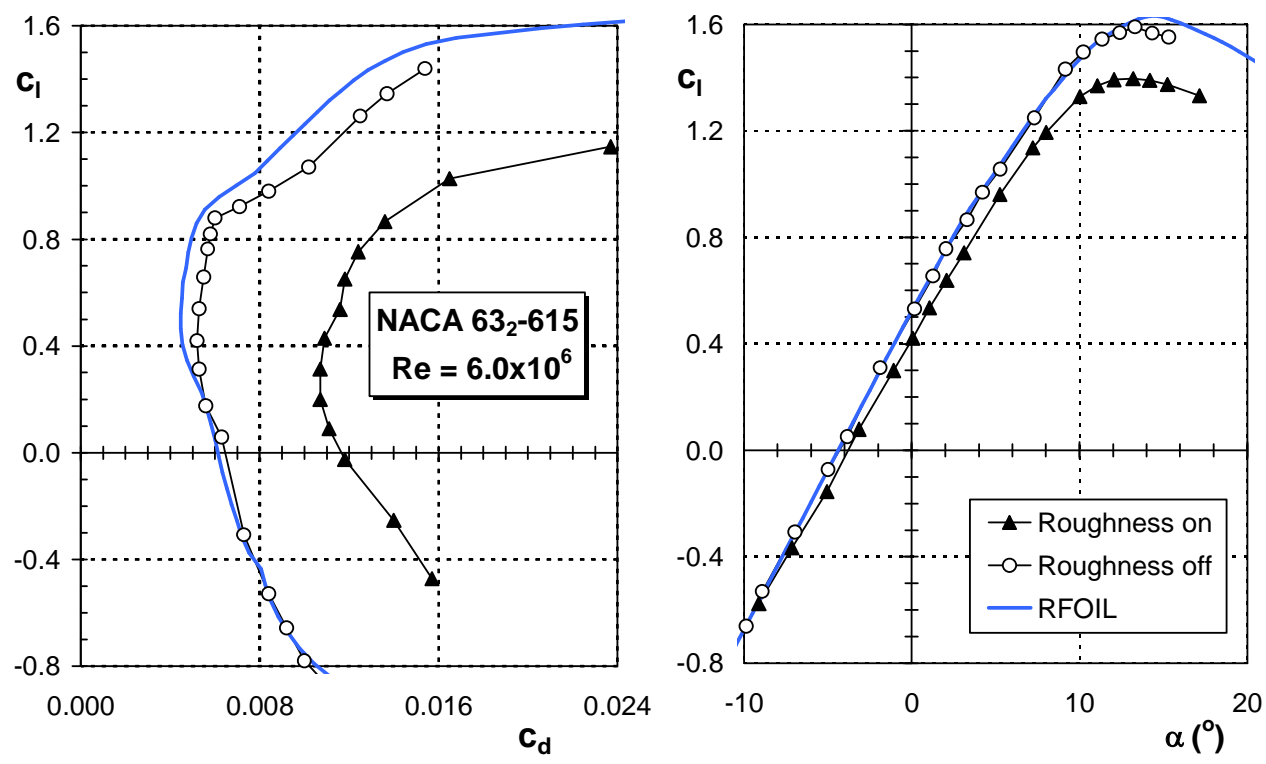

Figure 8. The clean and rough performance of airfoil NACA 63-615 after modification of the zero-lift angles. RFOIL calculations with $n=9$ 
Figure 8 depicts the situation after modification of the zero-lift angles. Also in the graph the RFOIL calculated performance of the airfoil. The picture shows a good match of the theoretical and experimental lift curves and the expected lower calculated drag coefficient (about $9 \%$ to 10\%) in the airfoil smooth configuration.
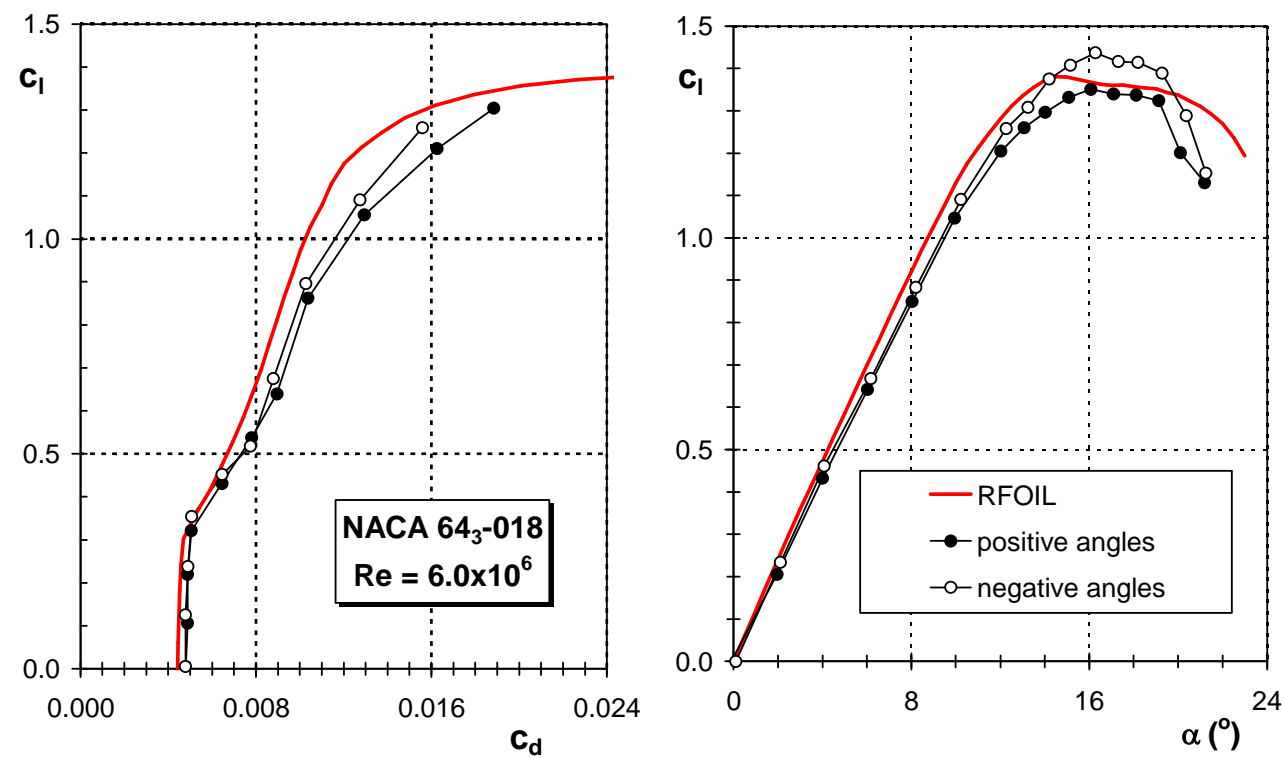

Figure 9. The difference between the lift and drag coefficients of a symmetric airfoil at positive and negative angles of attack.

\section{Maximum lift values}

The maximum lift coefficient is important in view of the maximum static loads on the blade. The experimental value of $\mathrm{C}_{1, \max }$ depends on the tunnel test section turbulence, the model blockage in terms of the model chord tunnel height ratio in combination with the wind tunnel wall correction scheme and the accuracy and state of the wind tunnel model. As an example figure 9 gives the measured performance of the airfoil NACA $64_{3}-018$ at a Reynolds number of $6 \times 10^{6}$. The figure demonstrates a clear difference in the experimental maximum lift coefficients whereas one would expect the lift curves for the positive and negative angles of this symmetric airfoil to coincide. The lift curve in the graph has been corrected for a 0.11 degrees zero lift angle offset. In general these differences can be attributed to differences in the model upper and lower surface contours (especially in the leading edge region) or an aberration in the angle of attack setting mechanism.

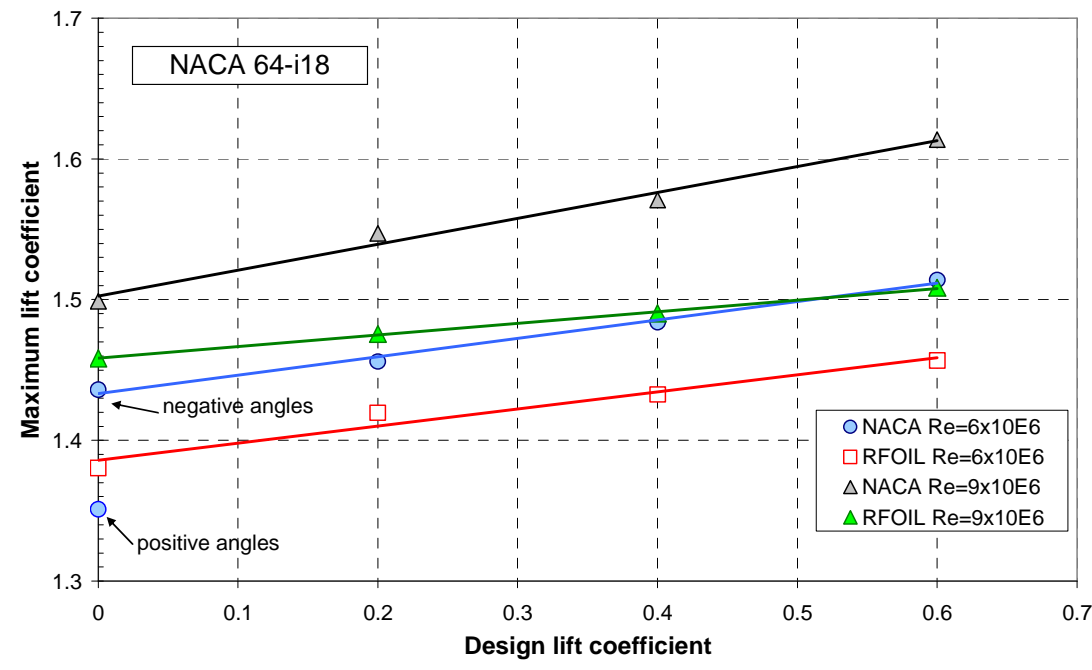

Figure 10. The measured and calculated maximum lift coefficients for $18 \%$ thick airfoils from the NACA 64 6-digit series. RFOIL calculations with $n=9$

American Institute of Aeronautics and Astronautics 
In this case there is a 0.09 difference in value of the maximum lift coefficients. Without any additional information one would not know what value to pick, the more since the calculated curve gives a value more or less in between the two values, albeit at a different angle of incidence.

The next picture shows us that the most likely value in this case is the one from the negative angles of attack. Figure 10 gives the measured and RFOIL calculated maximum lift coefficients for the NACA 64-i18 series at the Reynolds numbers of $6 \times 10^{6}$ and $9 \times 10^{6}$. The calculated values are consistently lower with a $3.5 \%$ difference at a Reynolds number of $6 \times 10^{6}$. For the higher Reynolds number the difference between calculated and experimental maximum lift coefficient increases with increasing design lift coefficient to about $6.5 \%$ for the NACA 64-618. Adversely, figure 4 shows an over prediction of the maximum lift coefficient at negative angles.

In the public domain no experimental data can be found to compare with the LTPT measurements at these high Reynolds numbers. For $\mathrm{Re}=3 \times 10^{6}$ data from the low-speed wind tunnel in Stuttgart, Germany can be used ${ }^{6}$. Figure 11 shows the lift curves of three NACA airfoils from the 63 series measured in both wind tunnels. In the German wind tunnel the lift was also derived from the wall pressures. The Stuttgart maximum lift coefficients appear to be consistently lower, for the non-symmetric airfoils about $6.5 \%$ compared to the LTPT data. The RFOIL calculations match the LTPT maximum lift well at $\mathrm{Re}=3 \times 10^{6}$.

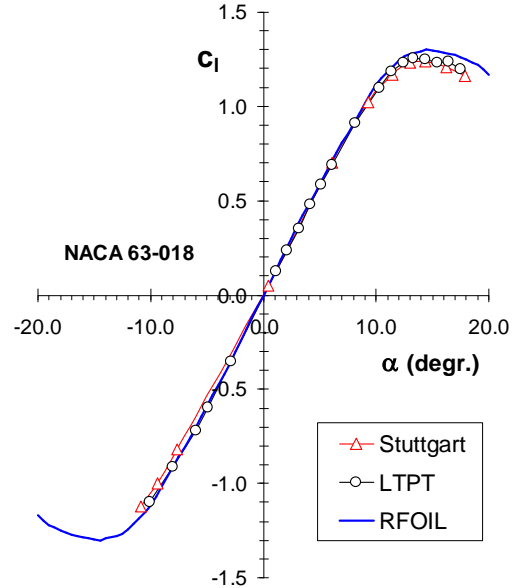

(a)

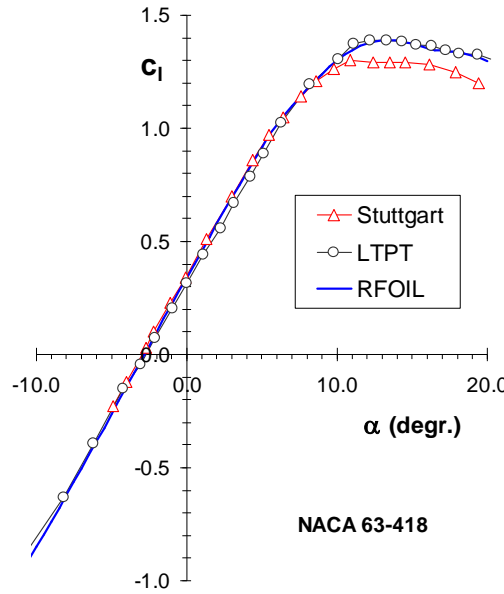

(b)

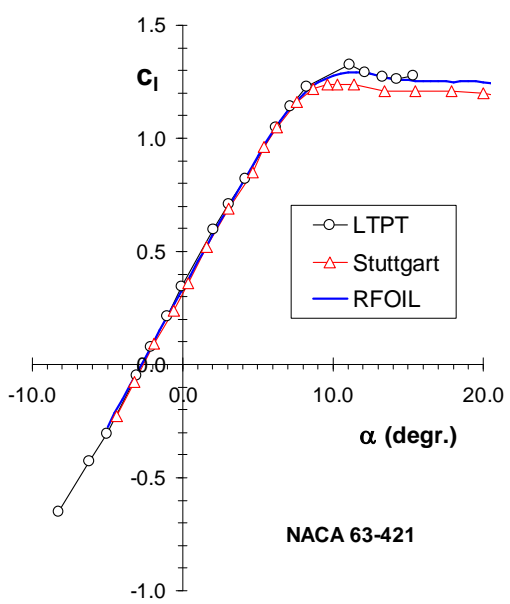

(c)

Figure 11. A comparison of NACA-airfoil lift measurements in the LTPT and the low-speed tunnel of the IAG Stuttgart ${ }^{6} . \operatorname{Re}=3 \times 10^{6}$.

Comparing the RFOIL calculations with the LTPT measurements, it seems that, with respect to the maximum lift coefficient, the predictive value of the calculations for this type of airfoils decreases with increasing Reynolds number. As mentioned before, there are little data available to serve as a check. Measurements coming closest are the ones performed in the cryogenic wind tunnel of the DNW-KKK in Cologne, Germany ${ }^{7}$ on the $30 \%$ thick airfoil DU 97-W-300Mod. Figure 12 shows the maximum lift coefficients of this airfoil measured up to a Reynolds number of $10 \times 10^{6}$ at various Mach numbers. Also in the graph the calculated maximum lift coefficients at two distinct values of the amplification factor $n$, to show the difference for a situation with increased turbulence $(n=5)$, since the cooling of the tunnel gas necessary to reach the high Reynolds numbers induces a higher turbulence intensity. The modification to the base airfoil consisted of a reduction of the trailing edge thickness from $1.74 \% \mathrm{c}$ to $0.49 \% \mathrm{c}$, which resulted in a small reduction of the lift coefficients. The low-turbulence tests results of the base airfoil are shown as well. This comparison shows an over prediction of the $\mathrm{C}_{1, \max }$ by the RFOIL calculations (with the Mach number set to 0.2 ), when the usual amplification factor $n=9$ is used. However, when the increased turbulence in the test section is accounted for, the calculated maximum values match the tunnel data quite well. Of course one could question the fact that the right turbulence intensity is represented by $n=5$, however the figure shows that using RFOIL not necessarily leads to under prediction of the maximum lift coefficient at the higher Reynolds numbers. 
If and to what extent the RFOIL code fails to predict the right maximum lift coefficient remains inconclusive from the foregoing.

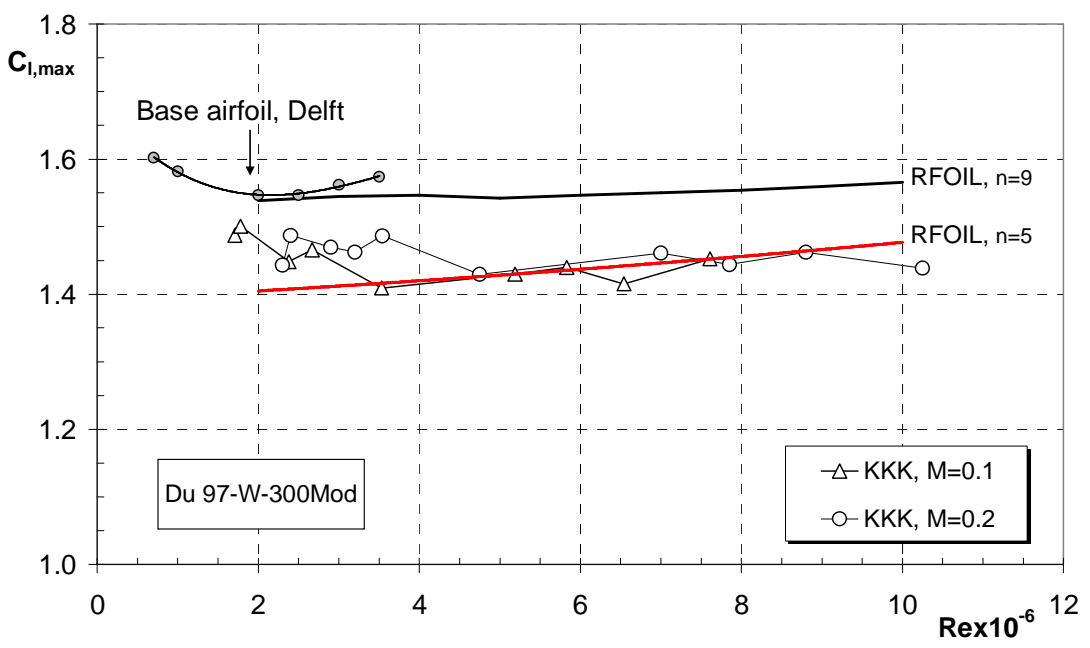

Figure 12. The variation of the maximum lift coefficients with Reynolds number as measured and calculated for airfoil DU 97-W-300Mod.

\section{E. Airfoil drag}

The figures 4, 8 and 9 have already shown that the drag coefficient predicted by XFOIL / RFOIL is consistently lower compared to the measurements. Figure 13 shows the measured and RFOIL predicted drag characteristics of airfoil NACA $64-618$ for Reynolds numbers of $3 \times 10^{6}$ and $9 \times 10^{6}$. The predicted drag coefficient has been multiplied by a factor of 1.09 .
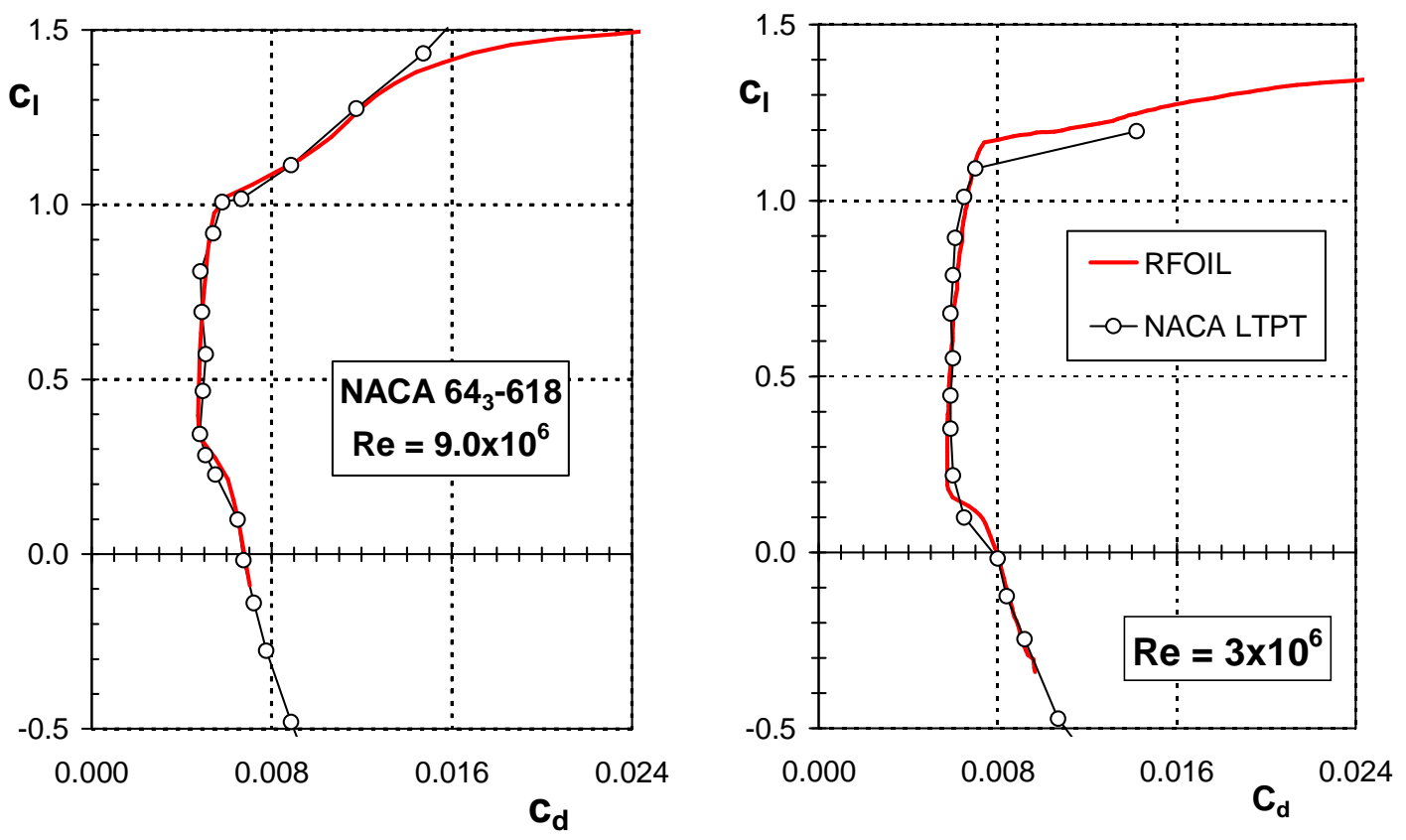

Figure 13. The RFOIL predicted drag coefficient (multiplied by a factor of 1.09) compared to the LTPT wind tunnel measurements.

The figure shows that there is a good match between the predicted drag data with a 9\% increase and the wind tunnel data. In fact this factor of 1.09 to match the experimental values is applicable to the predicted drag of most airfoils 
and - as figure 13 shows - in a relatively broad Reynolds numbers range as well. The LTPT drag data are found to be in good agreement with data from other sources. At the lower end of the low drag region RFOIL seems to predict a faster transition shift towards the lower surface leading edge as the angle of attack is reduced. It can be concluded that, using a 9\% higher drag coefficient, RFOIL may be used for prediction of the drag and the maximum lift to drag ratio of airfoils in the clean configuration at Reynolds numbers up to $9 \times 10^{6}$.

\section{F. Roughness effects}

The contamination of rotor blades can sometimes be significant. The degree of contamination may vary, depending on the turbine location and the time of the year. Airfoils are chosen for their low sensitivity to roughness effects, but unfortunately the degradation in performance due to a contaminated leading edge is difficult to predict. Simply specifying a fixed transition location near the airfoil leading edge will not do, since this does not incorporate the increase in boundary layer thickness and momentum loss due to the roughness elements causing the transition. The effect on the airfoil performance of roughness elements is typically something that can be studied during wind tunnel tests. In many experiments zigzag tape is used to trip the boundary layer and depending on the location and the thickness of the tape this gives a fairly good idea of the sensitivity of the airfoil to premature transition.

However, in reality things may be even worse than the configuration with zigzag tape. The NACA tests with wraparound roughness may be considered as a worst case scenario. Figure 14 gives the performance of the airfoils of figure $2 \mathrm{a}$ with NACA standard roughness consisting of no. 60 grid roughness wrapped around the leading edge from the lower surface $8 \%$ chord station to the upper surface $8 \%$ station.
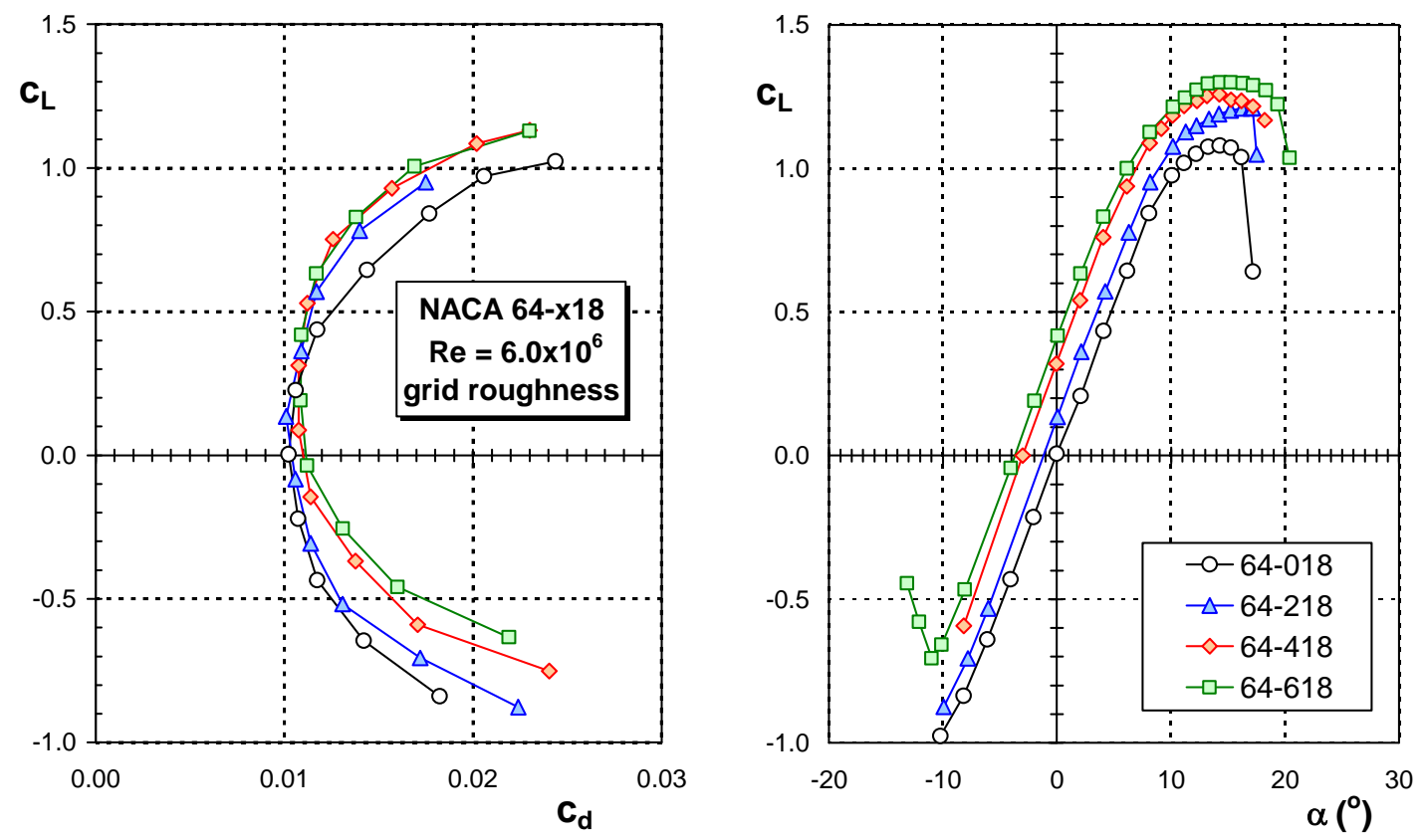

Figure 14. The effect of NACA standard roughness for a $18 \%$ thick NACA 64 series airfoil with various design lift coefficients.

Compared to the clean situation not only the drag has increased considerably, but due to the roughness the airfoils suffer from a significant loss in maximum lift coefficient.

Figure 15 depicts the variation of maximum lift with the maximum airfoil thickness for the $64-4 \mathrm{xx}$ series both in the clean situation and in the case of NACA standard roughness. It appears that due to the roughness the loss in maximum lift amounts to $18-20 \%$.

The lift curves in figure 14 do not show a regular increase with increasing camber. The zero-lift angles depicted in figure 16 show a deviating value for NACA 64-418. According to the measurements the zero-lift angle is -3.01 degrees, whereas the trend line indicates a value of -2.47 , a difference of 0.54 degrees. 


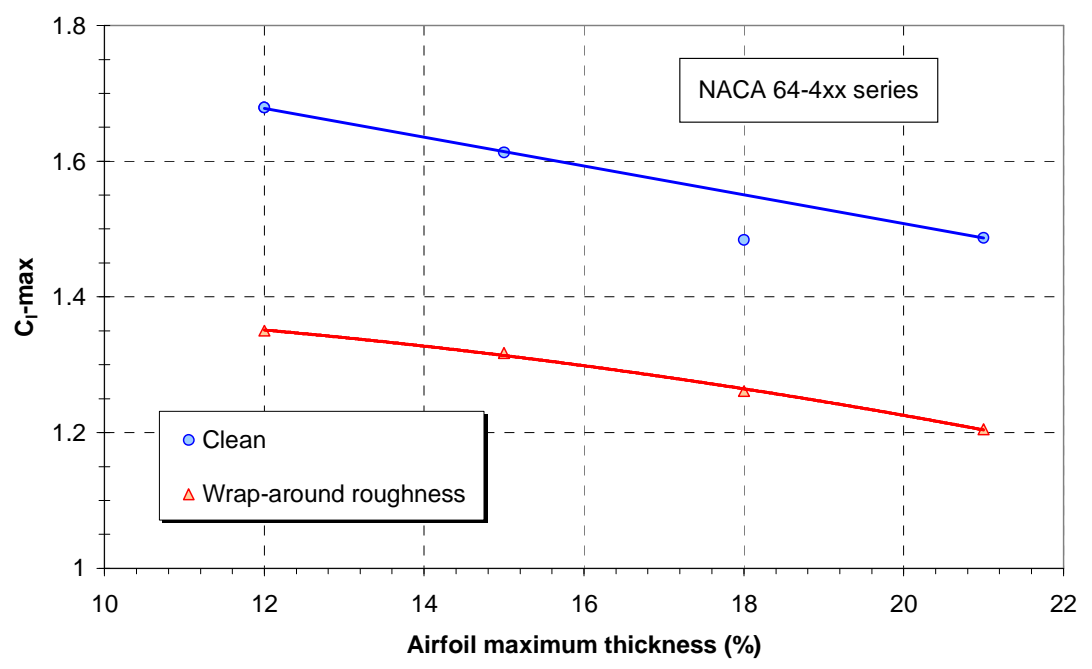

Figure 15. The variation of the maximum lift coefficient with airfoil thickness both in the clean case and with NACA standard roughness

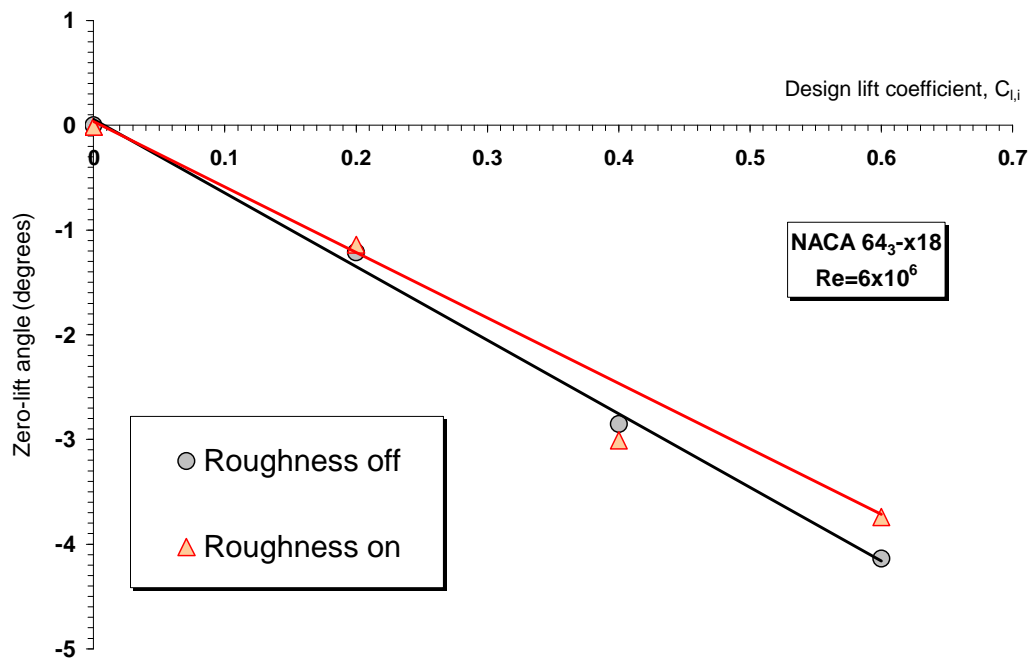

Figure 16. The effect of NACA standard roughness on the zero-lift angle of an $18 \%$ thick airfoil from the NACA 64 series with varying camber.

The difference of the effect of wrap-around roughness and roughness on discrete chord locations (NASA standard roughness) has been measured for airfoil $\mathrm{LS}(1)-0417^{8}$. NASA standard roughness consisted of $2.5 \mathrm{~mm}$ wide strips with no. 80 grid at $\mathrm{x} / \mathrm{c}=0.08$ both on the upper and lower surface. Clearly the wrap-around roughness induces a substantially higher loss in lift than the roughness on $8 \%$ of the chord. The maximum lift coefficient for this airfoil drops $18.5 \%$ from 2 to 1.63 whereas the NASA standard roughness only reduces lift with $4.5 \%$. The minimum drag coefficient increases about $50 \%$ due to the wrap-around roughness, which is significantly larger than measured for the NACA 64-series showing an increase of about $20 \%$.

Since the effect of leading edge contamination is significant and difficult to predict and as long as it is unclear what degree of contamination may be expected on wind turbine blades it remains necessary to perform wind tunnel tests on new airfoils at the appropriate Reynolds numbers. To establish the effect of leading edge contamination on the turbine performance side by side tests of a turbine with clean(ed) blades and one with an untreated rotor may give valuable information, also as input to the design of new dedicated airfoils. 


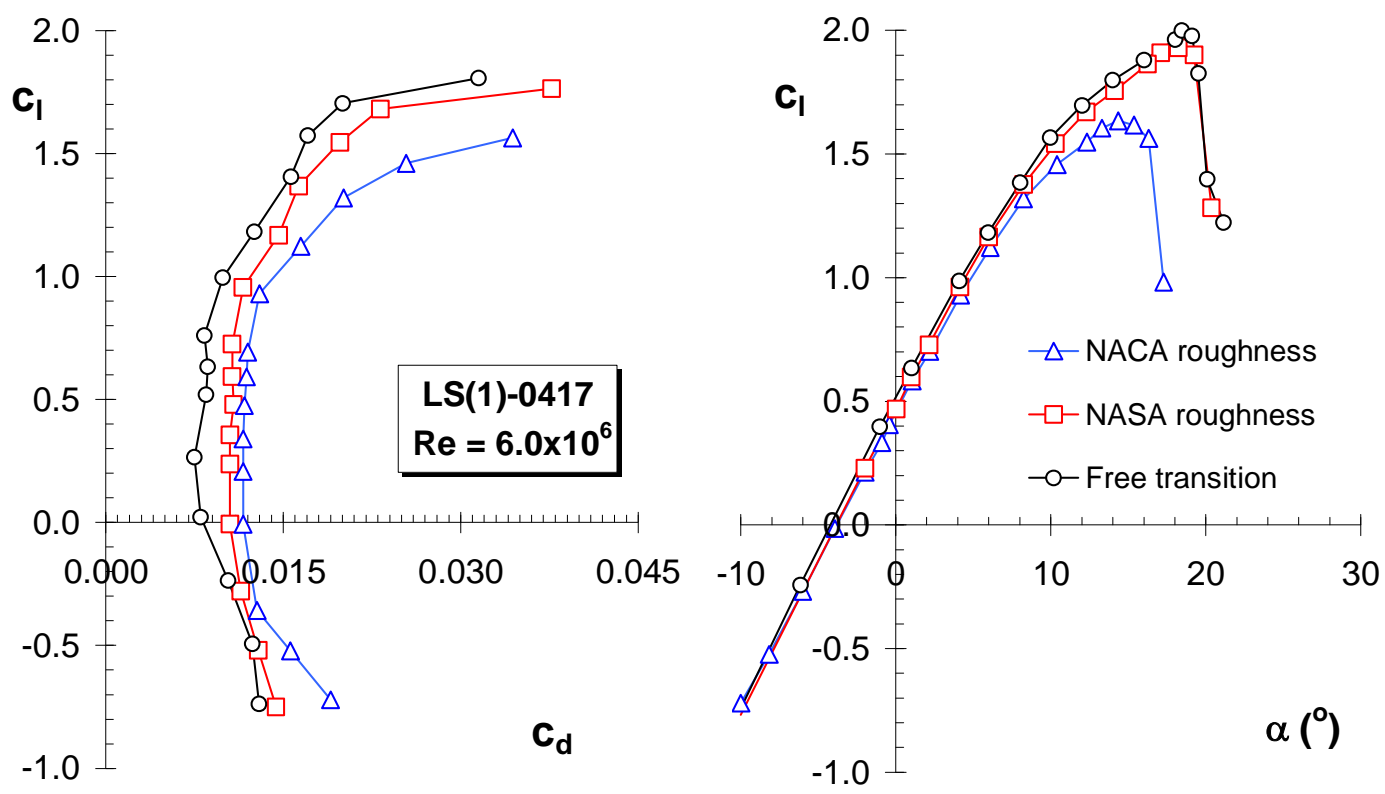

Figure 17. The effect of NACA standard roughness and NASA standard roughness on the performance of airfoil LS(1)-0417

\section{Conclusions}

The two-dimensional aerodynamics characteristics of the NACA 63 and 64 six-digit series of airfoils measured in the NASA LTPT have been investigated, with a view to verify RFOIL calculations at high Reynolds numbers. The following conclusions can be drawn:

- $\quad$ The zero-lift angle of the NACA 64-618 airfoil needs to be adjusted with -0.4 degrees.

- $\quad$ The zero-lift angle of The NACA 63-615 needs to be corrected with -0.87 degrees in the smooth case and with +1 degree in case of wrap around roughness.

- $\quad$ The maximum lift coefficients predicted with RFOIL match the LTPT data well at $\operatorname{Re}=3 \times 10^{6}$, but under predict the $C_{1, \max }$ at $\operatorname{Re}=6 \times 10^{6}$ by $3.5 \%$, up to $6.5 \%$ at $\operatorname{Re}=9 \times 10^{6}$.

- It is uncertain if the established differences in lift between experiment and calculations are caused by a constant bias in the measurements or by the fact that the RFOIL code fails to predict the right level of maximum lift.

- $\quad$ RFOIL consistently under predicts the drag coefficient. The difference is about $9 \%$ for a wide range of airfoils and Reynolds numbers

- $\quad$ NACA standard roughness causes a reduction in the lift coefficient of $18 \%$ to $20 \%$ for most airfoils from the NACA 64 series

- $\quad$ The zero-lift angle of airfoil NACA 64-418 with wrap-around roughness needs a correction of +0.54 degrees.

- Wind tunnel experiments and side-by-side tests in the field with one clean rotor need to be done to be able to better predict the effects of roughness.

\section{References}

${ }^{1}$ Abbott, I.H., and von Doenhoff, A.E., Theory of Wing Sections, Dover publications, Inc. New York 1958

${ }^{2}$ Allen, H.J. and Vincenti, W.G., "Interference in a Two-dimensional-flow Wind Tunnel with Consideration of the Effect of Compressibility”. NACA Report no. 782, 1944

${ }^{3}$ Abbott, I.H., von Doenhoff, A.E., and Stivers, L.S., "Summary of Airfoil Data". NACA Report no. 824, 1945 
${ }^{4}$ Rooij, R.P.J.O.M. van, "Modification of the boundary layer in XFOIL for improved airfoil stall prediction". Report IW-96087R, Delft University of Technology, September 1996. Delft, The Netherlands.

${ }^{5}$ Fuglsang, P and Bove, S., "Wind Tunnel Testing Of Airfoils Involves More Than Just Wind Tunnel Wall Corrections". Proceedings of the European Wind Energy Conference 2008, Brussels, Belgium. June 2008

${ }^{6}$ Althaus, D., Airfoils and Experimental Results from the Laminar Wind Tunnel of the Institut für Aerodynamik und Gasdynamik der Universität Stuttgart. IAG Stuttgart 1995

7 Timmer, W.A. and Schaffarczyk,A.P. "The Effect of Roughness at High Reynolds Numbers on the Performance of DU 97-W-300Mod". Proceedings of the conference The Science of making Torque from Wind, April 2004, Delft, The Netherlands. pp. 71-77.

${ }^{8}$ McGhee, R.J. and Beasley, W.D., "Low-Speed Aerodynamic Characteristics of a 17-Percent-thick Airfoil Section Designed for General Aviation Applications". NASA TN D-7428, 1973. 